NOTES AND CORRESPONDENCE

\title{
Extraction of Major Teleconnection Patterns Possibly Associated with the Anomalous Summer Climate in Japan
}

\author{
Seiji WAKABAYASHI and Ryuichi KAWAMURA \\ Department of Earth Sciences, Toyama University, Toyama, Japan
}

(Manuscript received 25 March 2004, in final form 16 July 2004)

\begin{abstract}
Four teleconnection patterns that are possibly associated with the anomalous summer climate in Japan and the surrounding regions, were extracted by applying empirical orthogonal function and regression analyses to stream function anomalies. The two teleconnection patterns prevailing over northern Eurasia, especially in early summer, called the Europe-Japan (EJ) 1 and EJ2, are linked with the variability of the Okhotsk high. The third teleconnection pattern, called the West Asia-Japan (WJ), is a stationary wave-train pattern along the upper-level subtropical jet from West Asia to the central North Pacific, which is possibly excited by the anomalous convective heating of the Indian summer monsoon. The final teleconnection pattern is identified with the Pacific-Japan (PJ), found by Nitta. Teleconnection indices that account for the variability of those patterns are also defined on a monthly basis. The PJ and WJ patterns, which are more influential teleconnection patterns than the others, are closely related to the summer temperature anomalies, especially in northern and western Japan, respectively. EJ1 and EJ2 were amplified in several extreme summers, and they played a vital role in the cool summer of 2003 , along with PJ. A combination of two or three teleconnection patterns was also responsible for the occurrence of the recent extreme summers. Monitoring the major teleconnection patterns is very useful for understanding and forecasting the anomalous summer climate in East Asia.
\end{abstract}

\section{Introduction}

It has long been recognized that summer weather in the vicinity of Japan is governed by a combination of the North Pacific, the Bonin (Ogasawara), the Tibetan, and the Okhotsk highs prevailing in the boreal summer. A number of studies have examined these anticyclonic systems to determine why they fluctuate on intraseasonal and interannual scales. Some researchers noted that the tropical convective activity in the vicinity of the Philippine Sea

Corresponding author: Ryuichi Kawamura, Department of Earth Sciences, Toyama University, 3190 Gofuku, Toyama 930-8555, Japan.

E-mail: kawamura@sci.toyama-u.ac.jp

(C) 2004, Meteorological Society of Japan influences the anomalous summer climate in East Asia through changes in the North Pacific or Bonin highs (e.g., Nitta 1987; Huang and Li 1987; Kurihara and Tsuyuki 1987). Nitta (1987) defined such a remote forcing, associated with the western North Pacific summer monsoon activity (Murakami and Matsumoto 1994), as the Pacific-Japan (PJ) teleconnection pattern. By performing an ensemble of climate experiments, Kawamura et al. (1998) showed that anomalous SST forcing from the tropics is responsible for frequent occurrence of extraordinary summers in Japan after the late 1970s. A wave-train structure, such as PJ, is evident in the lower, rather than upper, troposphere (Kawamura et al. 1996).

Krishnan and Sugi (2001) suggested, in con- 
trast, that the Indian summer monsoon plays a significant role in the rainfall variability in Japan in the early summer. They postulated the existence of a mid-latitude continental route in the upper troposphere between India and Japan in terms of teleconnection. Wu and Wang (2002) also pointed out a dynamic link between the anomalous Indian heating, and East Asian circulation in the northern summer through upper-level wave propagation. Enomoto et al. (2003) emphasized that a stationary Rossby wave propagation along the Asian subtropical jet contributes to the formation of the Bonin high in a climatological sense. The phenomenon was called the Silkroad pattern. Thus, two contrasting views have been proposed in an effort to determine the possible causes of the anomalous summer climate, in association with the behavior of the North Pacific and Bonin highs.

It is well known, on the other hand, that the Okhotsk high is also an action center, and its anomalous persistence often triggers a cool summer, especially in northeastern Japan. The enhancement and persistence of the Okhotsk high tended to be accompanied by the occurrence of a blocking anticyclone in the middle and upper troposphere. Wang (1992) and Wang and Yasunari (1994) noted that, in the middle troposphere, a stationary wave-train pattern from northern Eurasia to the Sea of Okhotsk influences the blocking anticyclone in early summer. Nakamura and Fukamachi (2003) showed that the propagation of a stationary Rossby wave from northern Europe contributes to the blocking formation in early summer although, in May, synoptic-scale eddy-feedback processes are a primary factor for its formation. Ogi et al. (2003) reported the possibility that summer wave-train patterns across northern Eurasia are indirectly influenced by the North Atlantic Oscillation of the previous winter.

Thus, the previous studies suggest that at least three different teleconnection patterns are responsible for the anomalous summer climate in Japan and the surrounding regions. It is still uncertain, however, how these teleconnection patterns fluctuate on interannual scales, because the definitions for the patterns are somewhat obscure. If such important wave-train patterns were defined easily and objectively, it would be possible to improve seasonal fore- casting and clarify the possible mechanisms involved in the occurrence of extreme summers based on the dynamics of each wave-train pattern. The main objectives of this study are (1) to objectively extract major stationary wavetrain patterns that might affect the anomalous summer climate, particularly in Japan, and consider the findings of previous studies, and (2) to determine where the teleconnection patterns are excited.

\section{Data used and analysis procedure}

To extract and examine the major teleconnection patterns associated with the anomalous summer weather in Japan, information from the National Centers for Environmental Prediction/National Center for Atmospheric Research (NCEP/NCAR) global atmospheric reanalysis dataset (Kalnay et al. 1996) for the 30-year period 1974-2003 was used. In addition, monthly outgoing long-wave radiation (OLR) data with a spatial resolution of $2.5^{\circ} \times 2.5^{\circ}$ observed from NOAA satellites for the same period (except 1978) were used. First, an empirical orthogonal function (EOF) analysis was applied to the monthly stream function anomaly fields computed from the NCEP/ NCAR reanalysis data, and dominant stream function anomaly patterns were extracted during the boreal summer. Here, three sectors were selected: northern Eurasia $\left(30^{\circ}-170^{\circ} \mathrm{E}\right.$, $\left.50^{\circ}-70^{\circ} \mathrm{N}\right)$, mid-latitude Asia $\left(50^{\circ}-150^{\circ} \mathrm{E}, 25^{\circ}-\right.$ $\left.50^{\circ} \mathrm{N}\right)$, and the western North Pacific $\left(120^{\circ}-\right.$ $\left.160^{\circ} \mathrm{E}, 20^{\circ}-35^{\circ} \mathrm{N}\right)$. In addition, considering the results of previous studies, monthly stream function anomalies at $500-\mathrm{hPa}, 200-\mathrm{hPa}$, and $850-\mathrm{hPa}$ levels were used for the analysis in northern Eurasia, mid-latitude Asia, and western North Pacific, respectively. For the first two regions, the EOF analysis was applied to stationary wave stream function anomalies, that are defined as deviations from the zonal mean of stream functions, because zonally propagating modes were involved in this case. Secondly, a simultaneous regression analysis of the stream function anomalies with the time series of the leading modes of summer was performed to clarify the overall feature of each teleconnection pattern. Finally, some teleconnection indices related to the anomalous summer climate are defined to discuss the forcing regions of the wave-train patterns, and 
Table 1. Seventeen observational stations in Japan used for this study.

\begin{tabular}{|c|c|}
\hline & Station \\
\hline Northern Japan & $\begin{array}{c}\text { Abashiri, Nemuro, } \\
\text { Suttsu, Yamagata, } \\
\text { Ishinomaki }\end{array}$ \\
\hline Eastern Japan & $\begin{array}{c}\text { Fushiki, Nagano, Mito, } \\
\text { Iida, Choushi }\end{array}$ \\
\hline Western Japan & $\begin{array}{c}\text { Sakai, Hamada, Hikone, } \\
\text { Tadotsu, Miyazaki }\end{array}$ \\
\hline Others & Naze, Ishigakijima \\
\hline
\end{tabular}

their association with the occurrence of recent extraordinary summers in Japan. As seen in Table 1, the temperature records observed at 17 stations are used for this study. The Japan Meteorological Agency (JMA) uses these stations to compute mean temperatures throughout Japan.

\section{Characteristics of the teleconnection patterns}

Figure 1 shows the spatial patterns of the dominant modes appearing in the three sectors during the northern summer (June-August) for the period 1974-2003; these patterns are derived from the application of the simple EOF analysis to the monthly stream function anomaly data. The eigenvalues, proportions, and sampling errors of the leading modes are indicated in Table 2. The sampling errors are computed according to North et al. (1982), assuming that the data from each month is independent. The upper panel of Fig. 1 is the first $500-\mathrm{hPa}$ stream function mode in northern Eurasia, which is characterized by a zonal wave-train pattern. Since a positive anomaly is located near the Sea of Okhotsk, this mode is expected to influence the behavior of the Okhotsk high. The middle panel is the third mode with a pronounced positive anomaly over the Sea of Okhotsk, although it does not

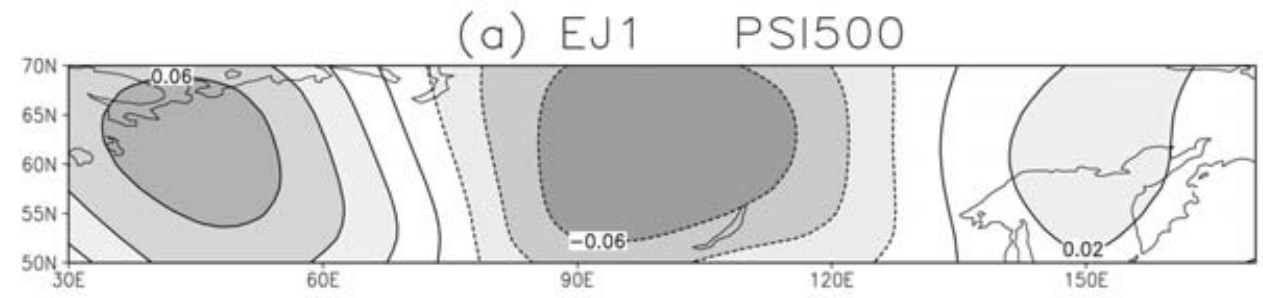

(b) EJ2 PSI500
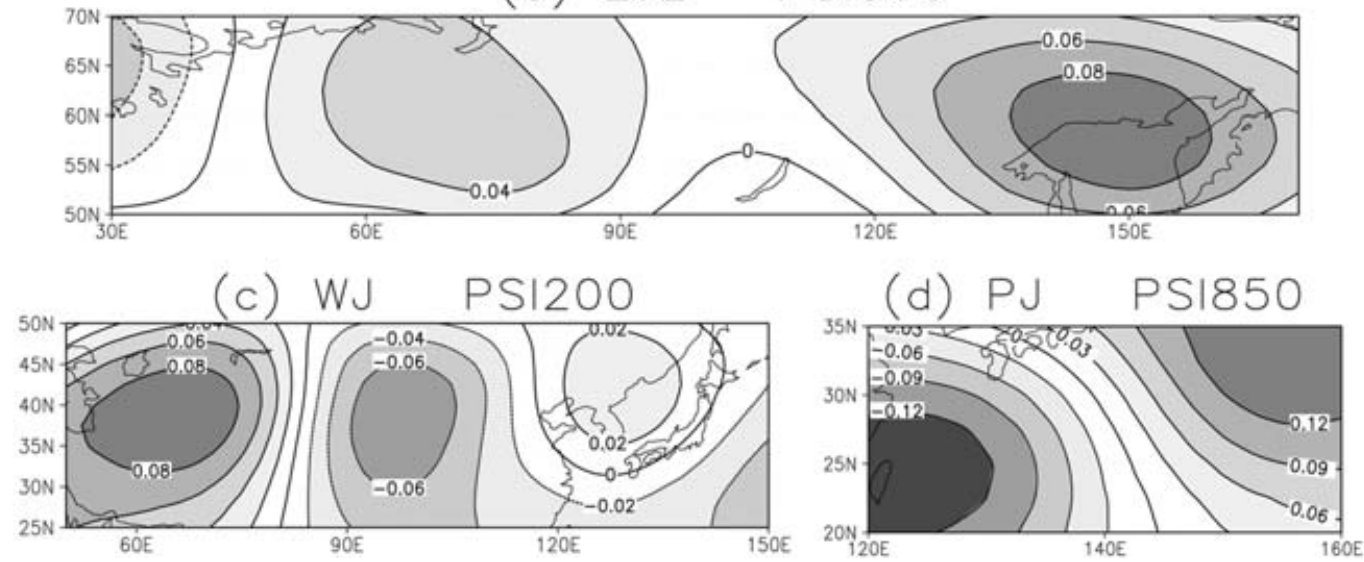

Fig. 1. Spatial patterns of teleconnection modes prevailing in (a, b) northern Eurasia, (c) midlatitude Asia, and (d) the western North Pacific during the boreal summer (June-August); these patterns are obtained from the application of a simple EOF analysis to monthly stream function anomaly data at 200-, 500-, and 850-hPa levels. See text for details. 
Table 2. The eigenvalues, proportions, and sampling errors of the leading modes in northern Eurasia, mid-latitude Asia, and the western North Pacific. Here, the errors imply intersample variability in each eigenvector. See North et al. (1982) for details.

\begin{tabular}{|l|c|c|c|c|c|c|c|c|c|c|}
\hline & \multicolumn{3}{|c|}{$\begin{array}{c}500-h P a \\
\text { (Northern Eurasia) }\end{array}$} & \multicolumn{2}{c|}{$\begin{array}{c}\text { 200-hPa stream function } \\
\text { (Mid-latitude Asia) }\end{array}$} & \multicolumn{3}{c|}{$\begin{array}{c}\text { 850-hPa stream function } \\
\text { (Western North Pacific) }\end{array}$} \\
\hline Mode & 1 & 2 & 3 & 4 & 1 & 2 & 3 & 1 & 2 & 3 \\
\hline Eigenvalue & 132.9 & 98.7 & 65.7 & 47.1 & 110.4 & 81.2 & 58.7 & 87.0 & 13.7 & 8.1 \\
\hline Proportion (\%) & 25.9 & 19.2 & 12.8 & 9.2 & 24.5 & 18.0 & 13.0 & 73.1 & 11.5 & 6.8 \\
\hline $\begin{array}{l}\text { Sampling } \\
\text { Error (\%) }\end{array}$ & 57.9 & 44.7 & 52.7 & 82.7 & 56.3 & 53.9 & 76.1 & 17.7 & 36.8 & 43.0 \\
\hline
\end{tabular}

necessarily indicate a typical wave-train pattern. The first and third modes are called the Europe-Japan (EJ) 1 and EJ2 patterns, respectively, for convenience. In this study, the second mode in northern Eurasia is not considered, because of the absence of significant anomalies in the vicinity of the Sea of Okhotsk.

The second mode of the $200-\mathrm{hPa}$ stream function in mid-latitude Asia is shown in Fig. 1c. This mode also exhibits a typical wave-train pattern with a salient positive anomaly over southwest and central Asia, which is hereafter called the West Asia-Japan (WJ) pattern. Similarly, the second $850-\mathrm{hPa}$ stream function mode in the western North Pacific is indicated in Fig. $1 \mathrm{~d}$, showing a dipole structure in a southwestnortheast direction. This mode can be identified with the PJ pattern. The first modes in midlatitude Asia and the western North Pacific that reveal the same signs throughout the analyzed regions are not considered in this study because the focus is, specifically, on the behavior of wave-train-like teleconnection modes. If we select the entire region of the Eurasian continent, including part of the western North Pacific Ocean, for the EOF analysis, the above four teleconnection patterns cannot be extracted as the leading modes and have less statistical significance. That is why the three regions were selected and why the EOF analysis was conducted for each region. As a result, the EJ1, EJ2, WJ, and PJ patterns are very robust (see Table 2 again), although EJ1 has a somewhat large intersample variability. The geographical shape of an EOF contains sampling errors to some extent due to a shortage of the data record.
The regression coefficients of $500-\mathrm{hPa}$ stream function anomalies with the summer (JJA) mean, and each monthly time series of EJ1 are shown in Fig. 2. The June pattern is most typical in terms of its wave-train structure, which is accompanied by two negative and two positive anomalies across northern Eurasia from Europe to the Sea of Okhotsk. According to additional regression analyses of stream function anomalies at other levels, these anomalies have a remarkable barotropic structure (figure not shown). The zonal wavelength of EJ1 is equivalent to about $10,000 \mathrm{~km}$. The July panel is similar to that in June, but August is significantly different from the other months. The EJ1 pattern prevails particularly in early summer, which is consistent with the previous studies.

In the same way, Fig. 3 shows the regression patterns of the $500-\mathrm{hPa}$ stream function anomalies with the time series of EJ2. As already pointed out, EJ2 is not necessarily a typical wave-train pattern, but it has two distinctive positive anomalies over the Sea of Okhotsk, and to the south of the Kara Sea. This spatial structure is evident in June and July, but it disappears in August. Since a positive anomaly over the Sea of Okhotsk is most significant in July, it appears that the EJ2 pattern is intimately linked with the variability of the Okhotsk high in that month. Another intriguing feature is the presence of a significant positive anomaly over the South China Sea in July and August. Such a presence cannot be seen in the EJ1 panels.

Figure 4 reveals the regression coefficients of $200-\mathrm{hPa}$ stream function anomalies, with the 

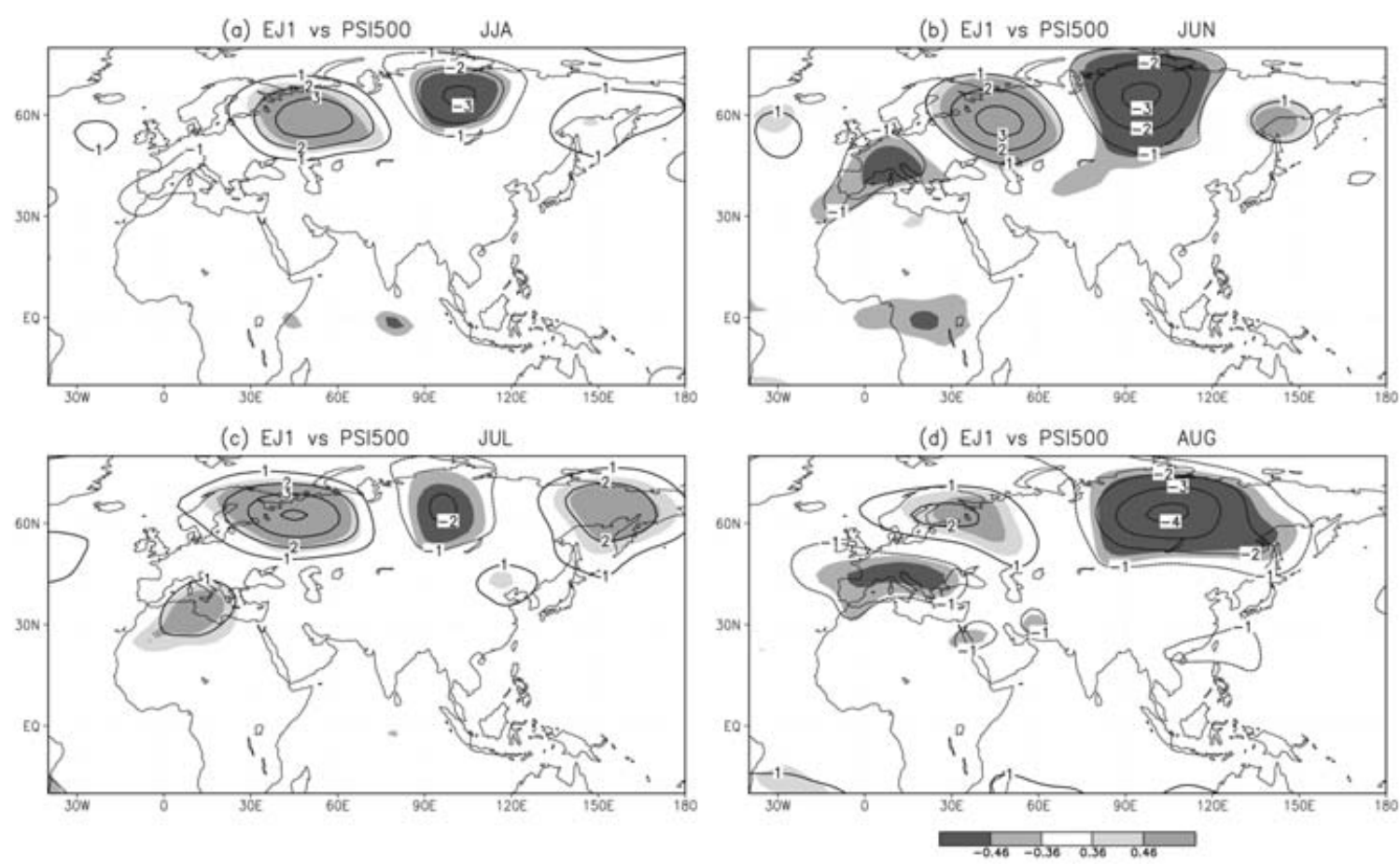

Fig. 2. Regression maps of the 500-hPa stream function with the (a) JJA mean, (b) June, (c) July, and (d) August time series of the EJ1 pattern. The contour interval of the regression coefficients is $1 \times 10^{6} \mathrm{~m}^{2} \mathrm{~s}^{-1}$. Zero contours are omitted. Heavy and light shadings indicate the regions where values satisfy the $1 \%$ and $5 \%$ levels of statistical significance, respectively, using a Student's $t$-test.
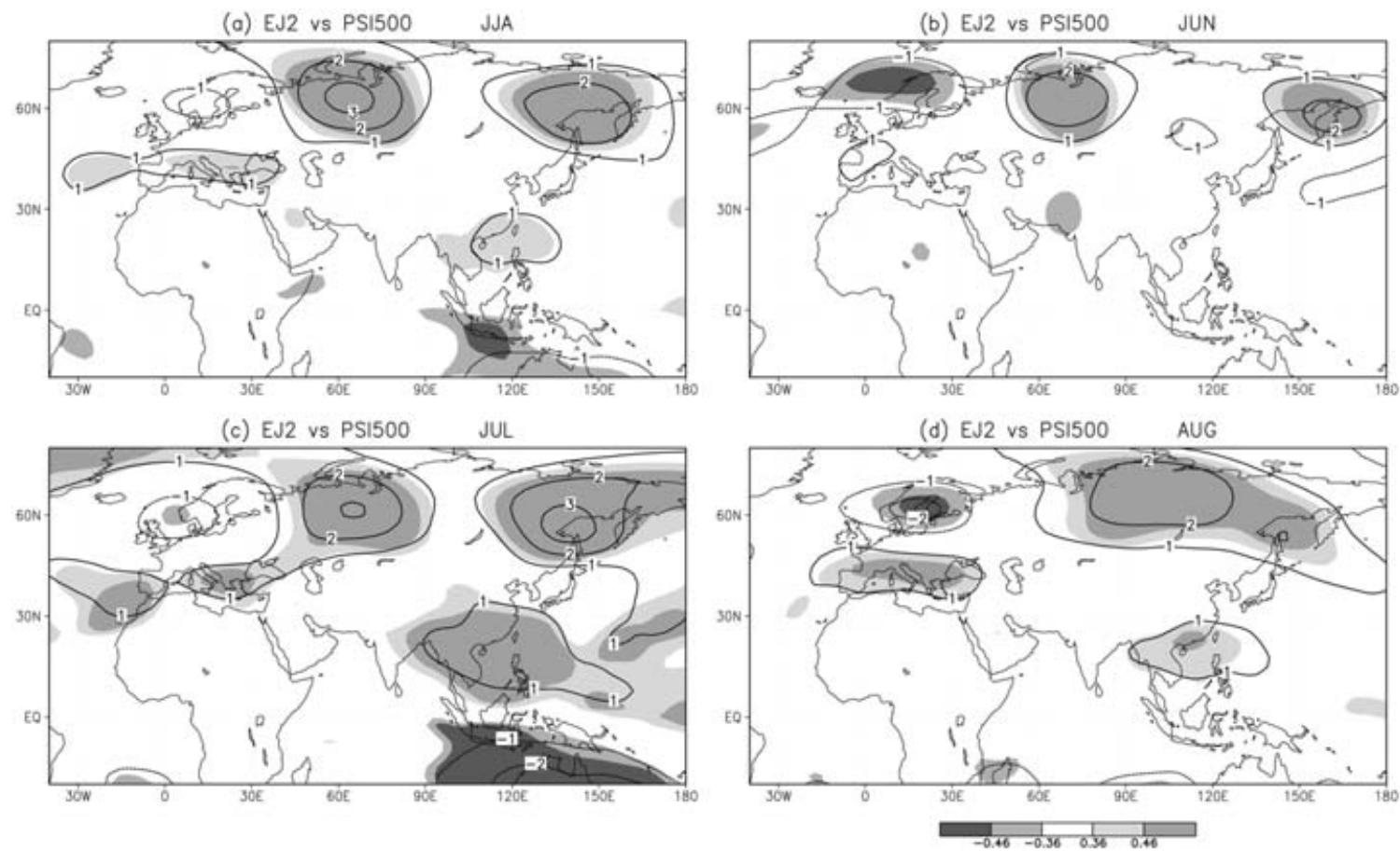

Fig. 3. As in Fig. 2, but for the EJ2 pattern. 
(a) WJ vs PSI200

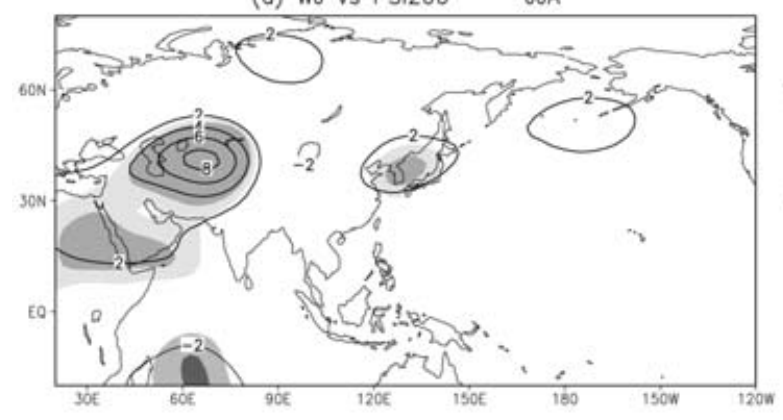

(c) WJ vs PSI200 JUL

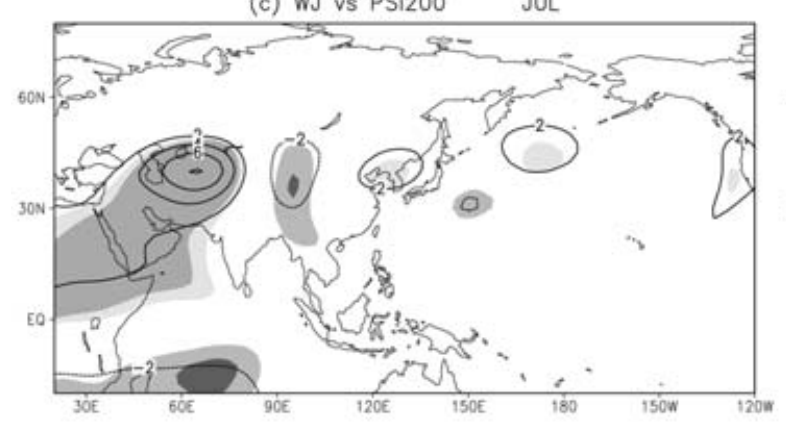

(b) WJ vs PSI200 JUN

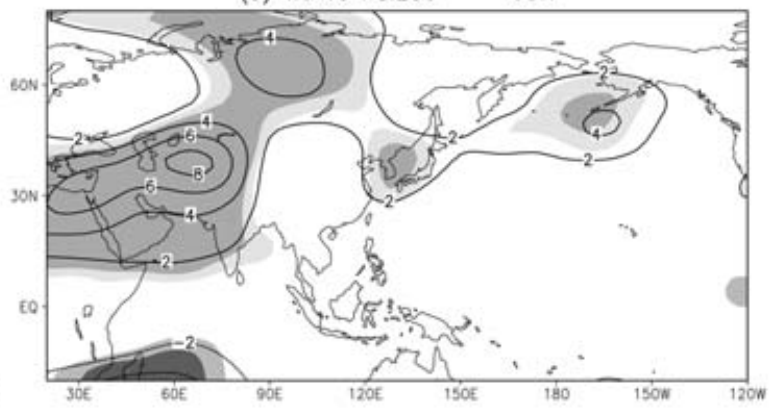

(d) WJ vs PSI200 AUG

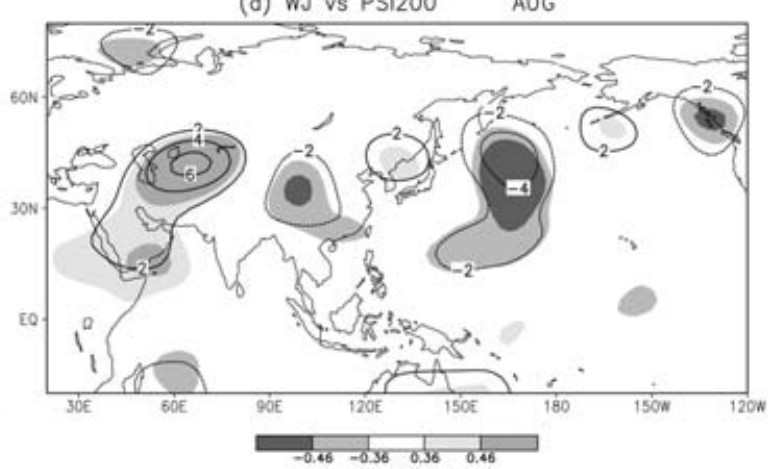

Fig. 4. As in Fig. 2, but for the WJ pattern. The contour interval of the regression coefficients is $2 \times 10^{6} \mathrm{~m}^{2} \mathrm{~s}^{-1}$.

JJA mean and each monthly time series of WJ. In June, a significant positive anomaly expands from central and southwest Asia to northeastern Africa. Another positive anomaly can be seen around Japan. This June pattern is similar to Fig. 3b of Krishnan and Sugi (2001), who emphasized an influence of the Indian summer monsoon activity on the Baiu rainfall in Japan through a mid-latitude continental route. Interestingly, the positive anomaly over central and southwest Asia is always seen in the summer months, corresponding to a westward expansion of the Tibetan high. Concurrent with the positive anomaly at the $200-\mathrm{hPa}$ level, a significant negative anomaly is located over southwest Asia in the lower troposphere (not shown), indicating a baroclinic structure. An obvious wave-train pattern across the North Pacific is present in August. It has a barotropic structure over the North Pacific (not shown), and its wavelength is about $6,000-7,000 \mathrm{~km}$. Such a wave-train pattern is also observed in July. The WJ pattern dominates along the upper-tropospheric subtropical jet from West Asia through the central North Pacific, which is clearly distinguished from the EJ1 and EJ2 patterns appearing over northern Eurasia.

The regression patterns of $850-\mathrm{hPa}$ stream function anomalies with the time series of the fourth teleconnection pattern, PJ, are shown in Fig. 5. The PJ pattern, which consists of a negative anomaly north of the Philippines and a positive anomaly east of Japan, is predominant throughout the summer. The positive anomaly east of Japan, having a marked barotropic nature, implies enhancement of the Bonin high or westward extension of the North Pacific high. The monthly patterns resemble each other. In an earlier study (Kawamura et al. 1996), summer climatological low-level westerlies were observed stretching all the way from the Philippine Sea, via Japan, to as far northeast as the Aleutian Islands, and these westerlies were presumed to act as a duct for wave energy propagation, such as PJ, to penetrate into higher latitude regions. Likewise, it is interesting to note that a weak but significant negative anomaly appears over the Sea of Okhotsk in August.

The next step is to define each teleconnection 
(a) PJ vs PSI850

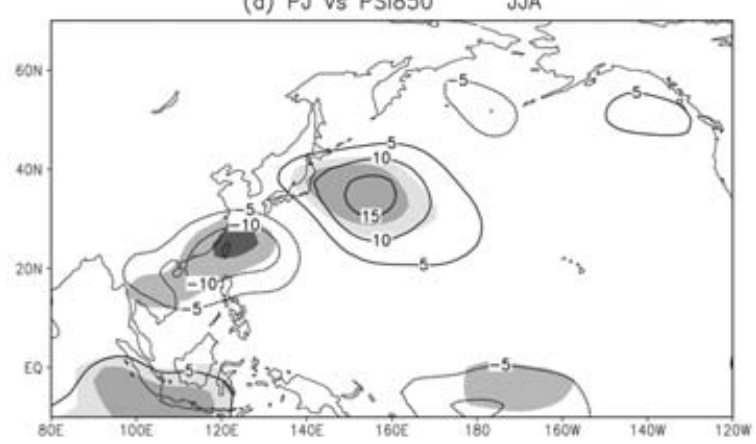

(c) PJ vs PSI850

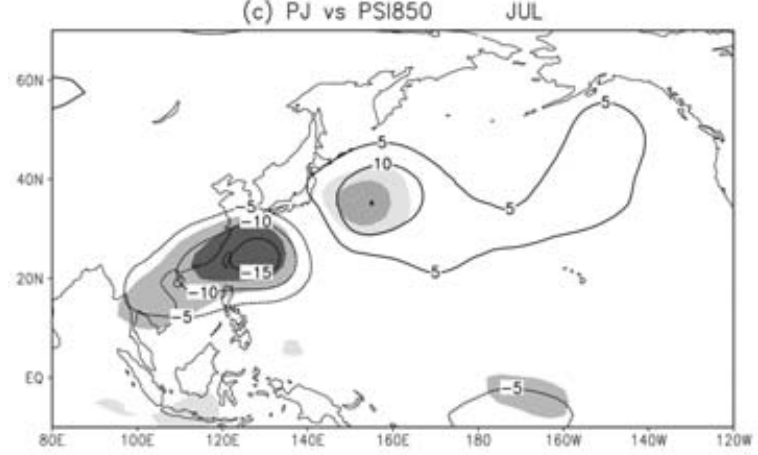

(b) PJ vs PS1850

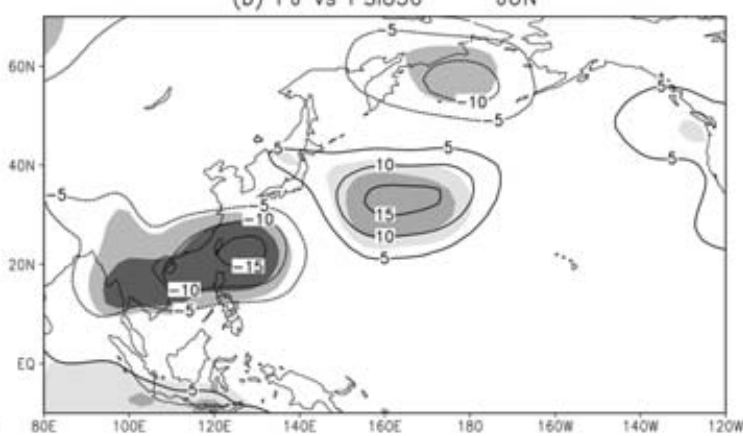

(d) PJ vs PSI850

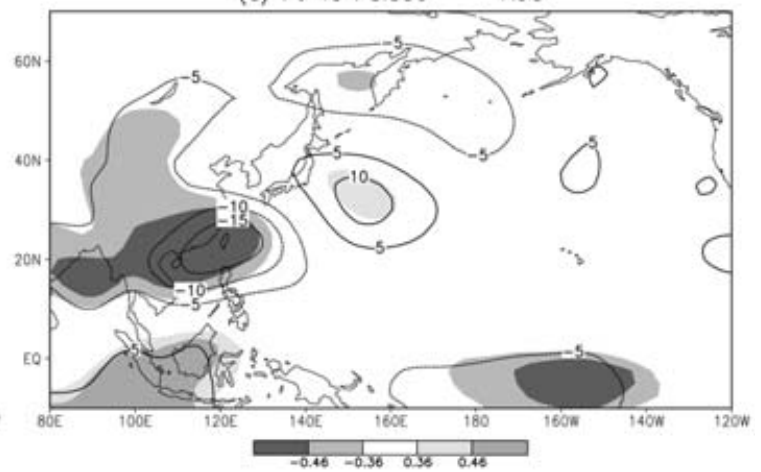

Fig. 5. As in Fig. 2, but for the PJ pattern. The contour interval of the regression coefficients is $5 \times 10^{5} \mathrm{~m}^{2} \mathrm{~s}^{-1}$.

index based on the results of the above EOF and regression analyses. Since an easy definition is better in terms of applicability, geopotential height anomalies are used instead of stream function anomalies to define each index. The following teleconnection indices are given in this study:

$$
\begin{aligned}
& E J 1= {\left[Z_{500}^{*}\left(45^{\circ} \mathrm{E}, 60^{\circ} \mathrm{N}\right)-Z_{500}^{*}\left(100^{\circ} \mathrm{E}, 65^{\circ} \mathrm{N}\right)\right.} \\
&\left.+Z_{500}^{*}\left(145^{\circ} \mathrm{E}, 60^{\circ} \mathrm{N}\right)\right] / 3 \\
& E J 2= {\left[Z_{500}^{*}\left(70^{\circ} \mathrm{E}, 60^{\circ} \mathrm{N}\right)\right.} \\
&\left.+Z_{500}^{*}\left(150^{\circ} \mathrm{E}, 57.5^{\circ} \mathrm{N}\right)\right] / 2, \\
& W J=\left[Z_{200}^{*}\left(65^{\circ} \mathrm{E}, 40^{\circ} \mathrm{N}\right)-Z_{200}^{*}\left(100^{\circ} \mathrm{E}, 40^{\circ} \mathrm{N}\right)\right.\left.+Z_{200}^{*}\left(130^{\circ} \mathrm{E}, 40^{\circ} \mathrm{N}\right)\right] / 3 \\
& P J=\left[Z_{850}^{*}\left(155^{\circ} \mathrm{E}, 35^{\circ} \mathrm{N}\right)\right. \\
&-\left.Z_{850}^{*}\left(125^{\circ} \mathrm{E}, 22.5^{\circ} \mathrm{N}\right)\right] / 2,
\end{aligned}
$$

where $Z_{200}^{*}, Z_{500}^{*}$, and $Z_{850}^{*}$ indicate the geopotential height anomalies at 200-, 500-, and $850-\mathrm{hPa}$ levels, respectively. The anomaly is relative to the 1974-2003 average. For confir- mation of the validity of these definitions, we present, in Fig. 6, the regression coefficients of geopotential height anomalies at corresponding levels, with a normalized monthly time series of each teleconnection index. Furthermore, the shaded areas denote significant regression coefficients of OLR. The upper panels are the EJ1 and EJ2 regression patterns in June, and the lower panels are the WJ and PJ patterns in August. It turns out that very robust wavetrain patterns are derived, as well as the EOF modes in the stream function anomaly fields.

Looking at the EJ1 and EJ2 patterns prevailing over northern Eurasia, positive (negative) geopotential height anomalies are collocated with significant positive (negative) OLR anomalies. This feature suggests that the stationary wave-train patterns exert a significant influence on large-scale cloud activity. Similar wave-train patterns were also presented by Fukutomi et al. (2004), who examined an eastwest seesaw pattern of summer precipitation in northern Eurasia. In the EJ1 panel, interestingly, a significant negative OLR anomaly 
(a) EJ1 Index vs 2500 \& OLR JUN

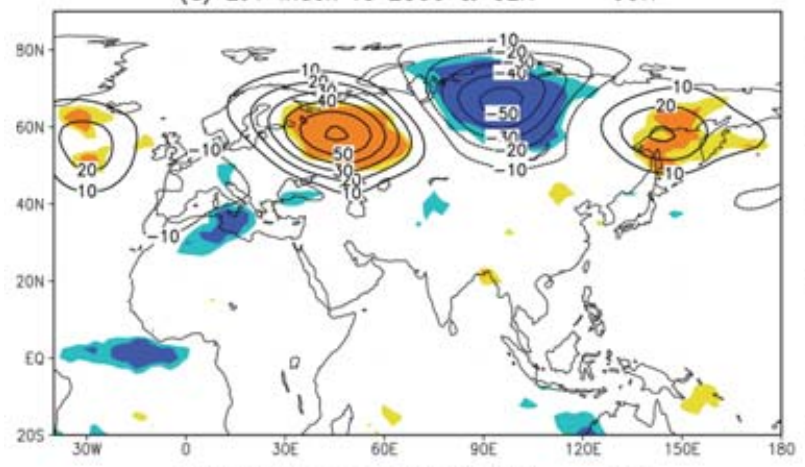

(c) WJ Index vs Z200 \& OLR AUG

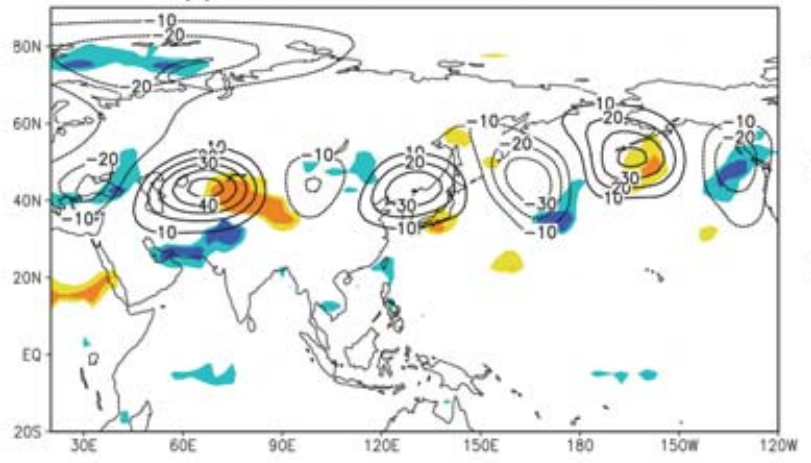

(b) EJ2 Index vs Z500 \& OLR

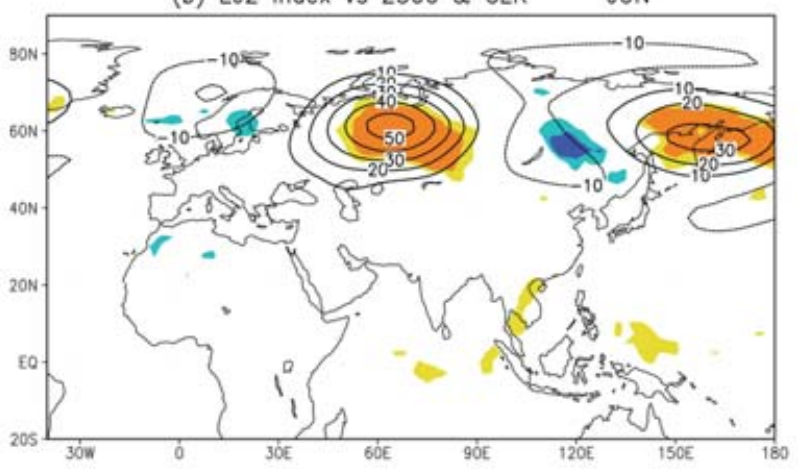

(d) PJ Index vs Z850 \& OLR AUG

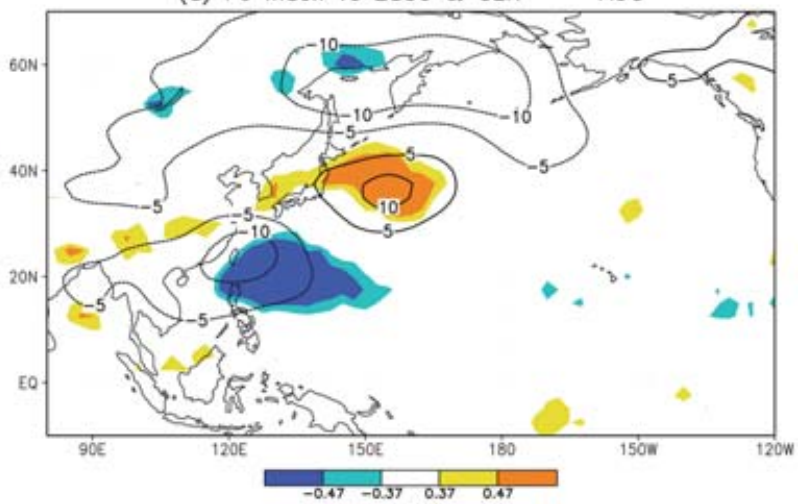

Fig. 6. (a) Regression map of the 500-hPa geopotential height and OLR with the normalized EJ1 index in June. The contour interval for the height is $10 \mathrm{~m}$. Zero contours are omitted. Heavy and light shadings indicate the regions where the regression coefficients of OLR satisfy the $1 \%$ and $5 \%$ levels of statistical significance, respectively, using a Student's $t$-test. (b) As in Fig. 6a, but for EJ2. (c) Regression map of the 200-hPa geopotential height and OLR with the normalized WJ index in August. The contour interval for the height is $10 \mathrm{~m}$. (d) Regression map of the 850-hPa geopotential height and OLR with the normalized PJ index in August. The contour interval for the height is $5 \mathrm{~m}$.

was observed along the equator of the Atlantic Ocean, which may suggest that there are some interactions between the tropical and midlatitude regions. The August pattern of WJ is in close conjunction with the enhanced convection over southwest Asia. Such a linkage is also evident in June and July (not shown). This indicates that diabatic heating relevant to the Indian summer monsoon activity is an important trigger for the excitation of WJ, which is consistent with Krishnan and Sugi (2001), Wu and Wang (2002), and Guan and Yamagata (2003). We confirmed that, during the boreal summer, the WJ index was highly correlated with the broad-scale monsoon circulation index proposed by Kawamura (1998). As is well known, the PJ pattern is related to the activity of the western North Pacific summer monsoon. In fact, the August pattern of PJ suggests that convective heating over the Philippine Sea is a probable cause of the PJ pattern. A positive anomaly east of Japan accompanies a significant positive OLR anomaly. The anomalous anticyclone organizing part of PJ seems to inhibit cloud activity there. The anomalous anticyclome that is responsible for part of PJ seems to inhibit the cloud activity there. Another discernible feature in this panel is that a zonally elongated negative anomaly in the vicinity of the Sea of Okhotsk connects the PJ pattern, implying an influence of PJ on the Okhotsk high activity in August (see also Fig. 5d). Thus, the two summer monsoon activities (i.e., the western North Pacific summer monsoon and 

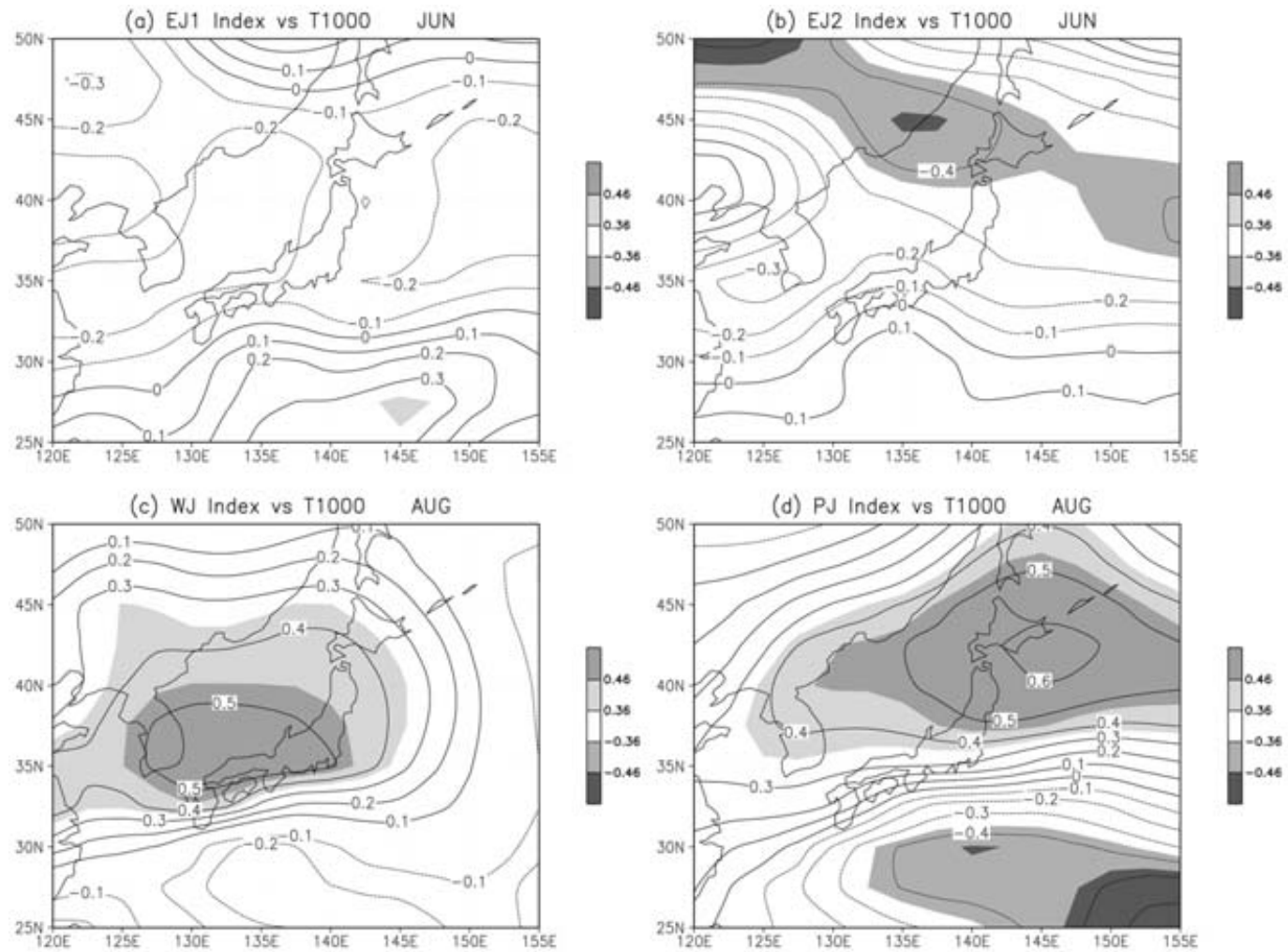

Fig. 7. (a) Correlation map of the 1000-hPa temperature with the normalized EJ1 index in June. The contour interval is 0.1 . Heavy and light shadings indicate the regions where the correlation coefficients satisfy the $1 \%$ and $5 \%$ levels of statistical significance, respectively, using a Student's $t$-test. (b) As in Fig. 7a, but for EJ2. (c) Correlation map of the 1000-hPa temperature with the normalized WJ index in August. (d) As in Fig. 7c, but for PJ.

the Indian summer monsoon) play a vital role in the anomalous geopotential heights in Japan and the surrounding regions through teleconnection.

\section{Implications for the recent extreme summers in Japan}

As previously stated, the anomalously persistent North Pacific, Bonin, Tibetan, and Okhotsk highs may be the causes of the extreme summers in Japan. For instance, the westward expansion of the North Pacific high, and eastward expansion of the Tibetan high, which cause the hot summer in Japan, may be attributed to the excitation of PJ or WJ or both. The development of the Okhotsk high may be attributed to the excitation of EJ1 or EJ2. Although, of course, detailed examinations are required to clarify the reasons for all unusual summers, in this study, the cross-correlations between the normalized time series of the four teleconnection indices and anomalous temperatures in Japan and the surrounding regions, are highlighted on a monthly basis from 1974 through 2003.

When the teleconnection patterns are prominent (such as those shown in Fig. 6), the correlation coefficients of $1000-\mathrm{hPa}$ temperature anomalies in the vicinity of Japan with the normalized monthly time series of each index are presented in Fig. 7. In August, the WJ pattern significantly affects the anomalous temperatures, especially in western Japan, whereas the PJ pattern is intimately related to the temperature anomalies, especially in northern Japan. In June, however, EJ1 has no significant correlations throughout Japan, although EJ2 influences the anomalous temperatures in northern Japan. Table 3 demonstrates the cross-correlation coefficients between the nor- 
Table 3. Cross-correlation coefficients between normalized monthly time series of the four teleconnection (PJ, WJ, EJ1, and EJ2) indices and summertime monthly temperature variations in Japan during the period 1974-2003. Note that double and single asterisks denote the coefficient with the $1 \%$ and $5 \%$ levels of statistical significance, respectively. Here, "all stations" indicates the 17 stations shown in Table 1.

\begin{tabular}{|c|c|c|c|c|c|c|c|c|c|c|c|c|}
\hline & \multicolumn{4}{|c|}{ PJ } & \multicolumn{3}{c|}{ WJ } & \multicolumn{3}{c|}{ EJ1 } & \multicolumn{3}{c|}{ EJ2 } \\
\cline { 2 - 11 } & Jun. & Jul. & Aug. & Jun. & Jul. & Aug. & Jun. & Jul. & Aug. & Jun. & Jul. & Aug. \\
\hline $\begin{array}{c}\text { All } \\
\text { stations }\end{array}$ & 0.28 & $\mathbf{0 . 4 9} * *$ & $0.43^{*}$ & $\mathbf{0 . 5 8} * *$ & 0.15 & $\mathbf{0 . 5 2} * *$ & -0.20 & -0.29 & -0.12 & -0.32 & -0.35 & -0.24 \\
\hline $\begin{array}{c}\text { Northern } \\
\text { Japan }\end{array}$ & $0.45^{*}$ & $\mathbf{0 . 5 3} * *$ & $\mathbf{0 . 6 1} * *$ & $\mathbf{0 . 4 8} * *$ & 0.13 & $0.42^{*}$ & -0.21 & -0.32 & -0.06 & $-0.42^{*}$ & $-0.39 *$ & -0.29 \\
\hline $\begin{array}{c}\text { Eastern } \\
\text { Japan }\end{array}$ & 0.24 & $\mathbf{0 . 5 0} * *$ & $0.37^{*}$ & $\mathbf{0 . 5 6} * *$ & 0.10 & $\mathbf{0 . 4 9} * *$ & -0.16 & -0.29 & -0.10 & -0.32 & $-0.38^{*}$ & -0.24 \\
\hline $\begin{array}{c}\text { Western } \\
\text { Japan }\end{array}$ & 0.19 & $0.37 *$ & 0.17 & $\mathbf{0 . 5 7} * *$ & 0.20 & $\mathbf{0 . 5 5 * *}$ & -0.23 & -0.22 & -0.11 & -0.22 & -0.26 & -0.15 \\
\hline
\end{tabular}

malized monthly time series of the four teleconnection indices, and the monthly summer temperature variations in Japan, based on the 17 observational stations compiled by the JMA (see also Table 1). It would appear that EJ1 has no significant impact on the summer climate in Japan, but, in July, significant correlations were detected at several stations in northern and eastern Japan (not shown). As expected, EJ2 is closely associated with the anomalous temperatures in northern and eastern Japan in early summer. As for mid-summer and late summer, PJ is a very influential teleconnection pattern in northern and eastern Japan. In contrast, WJ is more correlated with the temperature anomalies in western Japan than in northern Japan, but it has no significant correlations in July. Thus, distinctive regionality and seasonality are evident in the crosscorrelation field between the teleconnection indices and anomalous temperatures in Japan. These results suggest that the PJ and WJ patterns are more influential teleconnection patterns than the others. It was also determined that PJ and WJ are closely related to the temperature anomalies, particularly in northern and western Japan, respectively.

Guan and Yamagata (2003) reported that a barotropic Rossby wave-train pattern triggered by monsoonal heating is responsible for the extremely hot and dry summer of 1994. In fact, the normalized WJ index defined in this study has exceptionally positive values (1.68 in July and 1.43 in August), which is consistent with the study by Guan and Yamagata. In an earlier paper (Kawamura et al. 1998), it was suggested that anomalous convective heating over the Philippine Sea contributed a great deal to the frequent occurrence of extraordinary summers in Japan after the late 1970s through the dynamic process of the excitation of PJ. Considering the results of this study, it seems that the PJ pattern is responsible for the extreme summers, particularly in northern Japan in middle and late summer.

The amplification of EJ1 or EJ2 is also evident in some extremely cool summers. July 2003 was well documented as the coldest July in recent years. In that month, the EJ1 and EJ2 indices had remarkably positive values, along with a negative PJ index. There have been a few cases in which only one teleconnection pattern, such as PJ, brought about a severe summer, but it should be noted that a combination of two or three teleconnection patterns is also important for the occurrence of extraordinary summers.

\section{Summary}

In this study, four major teleconnection patterns possibly associated with an anomalous summer climate in Japan and the surrounding regions were extracted using EOF and regression analyses. The two teleconnection patterns prevailing over northern Eurasia, especially in early summer, called EJ1 and EJ2, are linked 
with the variability of the Okhotsk high. The third teleconnection pattern, called WJ, is a stationary wave-train pattern along the upperlevel subtropical jet from West Asia to the central North Pacific, and is possibly excited by the anomalous convective heating of the Indian summer monsoon. The final teleconnection pattern is identified with PJ. Distinct regionality and seasonality in the cross-correlation field were evident between the four teleconnection indices and anomalous temperatures in Japan. The PJ and WJ patterns, which affect the development or weakening of the Bonin high, or a westward extension or eastward retreat of the North Pacific high, are more influential teleconnection patterns than the others, and the former and latter patterns are closely related to the temperature anomalies, especially in northern and western Japan, respectively. EJ1 and EJ2 were amplified in several extreme summers, and they played a vital role in the cool summer of 2003, along with PJ.

Emphasis should be placed on the fact that monitoring these four teleconnection patterns is very useful for understanding the anomalous summer climate in East Asia. It cannot be concluded, of course, that linear regressions with the teleconnection indices account for all the extraordinary summers in Japan because midlatitude atmosphere has strong nonlinearity. Another deficiency should be pointed out. It remains uncertain how EJ1 is different from EJ2 in terms of wave dynamics. EJ1 is not independent of EJ2, according to their definitions. Nevertheless, the impact of the EJ1 pattern on the variability of the Okhotsk high cannot be ignored. On the basis of the dynamics of each teleconnection pattern, further investigations are needed to clarify the reasons for the occurrence of extraordinary summers in Japan and the surrounding regions. As previously stated, the first modes in mid-latitude Asia and the western North Pacific that have no wave-trainlike features have not been considered in this study. It is quite possible, however, that those modes are also related to the anomalous summer climate in Japan. This issue should also be considered in further studies.

\section{Acknowledgements}

Comments by three anonymous reviewers were extremely helpful. This research was supported by the research project "R\&D of hydrological modeling and water resources system" of JST/CREST, and by Grants-in-Aid (14540406) from the Japanese Ministry of Education, Sports, Culture, Science, and Technology.

\section{References}

Enomoto, T., B.J. Hoskins, and Y. Matsuda, 2003: The formation mechanism of the Bonin high in August. Quart. J. Roy. Meteor. Soc., 129, 157178.

Fukutomi, Y., K. Masuda, and T. Yasunari, 2004: Role of storm track activity in the interannual seesaw of summer precipitation over northern Eurasia. J. Geophys. Res., 109, D02109, doi:10.1029/2003JD003912.

Guan, Z., and T. Yamagata, 2003: The unusual summer of 1994 in East Asia: IOD teleconnections. Geophys. Res. Lett., 30, 1544, doi:10.1029/ $2002 G L 016831$.

Huang, R.H., and W.J. Li, 1987: Influence of the heat source anomaly over the western tropical $\mathrm{Pa}-$ cific on the subtropical high over East Asia. Proc. International conference on the general circulation of East Asia, 40-51.

Kalnay, E., and Coauthors, 1996: The NCEP/NCAR 40-year reanalysis project. Bull. Amer. Meteor. Soc., 77, 437-471.

Kawamura, R., T. Murakami, and B. Wang, 1996: Tropical and midlatitude 45-day perturbations over the western Pacific during the northern summer. J. Meteor. Soc. Japan, 74, 867-890.

Kawamura, R., 1998: A possible mechanism of the Asian summer monsoon-ENSO coupling. $J$. Meteor. Soc. Japan, 76, 1009-1027.

Kawamura, R., M. Sugi, T. Kayahara, and N. Sato, 1998: Recent extraordinary cool and hot summers in East Asia simulated by an ensemble climate experiment. J. Meteor. Soc. Japan, 76, 597-617.

Krishnan, R., and M. Sugi, 2001: Baiu rainfall variability and associated monsoon teleconnections. J. Meteor. Soc. Japan, 79, 851-860.

Kurihara, K., and T. Tsuyuki, 1987: Development of the barotropic high around Japan and its association with Rossby wave-like propagations over the North Pacific: Analysis of August 1984. J. Meteor. Soc. Japan, 65, 237-246.

Murakami, T., and J. Matsumoto, 1994: Summer monsoon over the Asian continent and the western North Pacific. J. Meteor. Soc. Japan, 72, 719-745.

Nakamura, H., and T. Fukamachi, 2003: Evolution and dynamics of summertime blocking over the Far East and the associated surface Okhotsk 
high. Quart. J. Roy. Meteor. Soc., 129, in press.

Nitta, T., 1987: Convective activities in the tropical western Pacific and their impact on the Northern Hemisphere summer circulation. J. Meteor. Soc. Japan, 65, 373-390.

North, G.R., T.L. Bell, and R.F. Cahalan, 1982: Sampling errors in the estimation of empirical orthogonal functions. Mon. Wea. Rev., 110, 699-706.

Ogi, M., Y. Tachibana, and K. Yamazaki, 2003: Impact of the wintertime North Atlantic Oscillation (NAO) on the summertime atmospheric circulation. Geophys. Res. Lett., 30, 1704, doi:10.1029/2003GL017280.

Wang, Y., 1992: Effects of blocking anticyclones in Eurasia in the rainy season (Meiyu/Baiu season). J. Meteor. Soc. Japan, 70, 929-950.

Wang, Y., and T. Yasunari, 1994: A diagnostic analysis of the wave train propagating from highlatitudes to low-latitudes in early summer. $J$. Meteor. Soc. Japan, 72, 269-279.

Wu, R., and B. Wang, 2002: A contrast of the East Asian summer monsoon-ENSO relationship between 1962-77 and 1978-93. J. Climate, 15, 3266-3279. 